\title{
Ideological and Political Education Research and Analysis based on Problem Students
}

\author{
Jianhong Li \\ Department of Common Courses, Leshan Vocational and Technical College, Leshan, Sichuan, China
}

\begin{abstract}
Educating and converting trouble students is an important task of teachers' work. The educators need to strive for the best, constantly being better; Digest, be able to achieve success one way or another; Completes the labor of duty, honesty and uprightness. Facing the problem of students, educators need to listen firstly, must be good at sensation, initiatively take responsibility, then with caring, guidance and enlightening his aggressive and self-confidence to correct shortcomings with reason, and then guide and encourage him to be positive, observe discipline, respect teacher and revere his teachings, to make it become the excellent students. Talk with students at a suitable place, points out the bright future, adjust to changing circumstances.
\end{abstract}

Keywords—problem students, ideological and political education, cases, basis, principle

\section{基于问题学生的思想政治教育探析}

\author{
李剑虹 \\ 乐山职业技术学院公课部, 乐山, 四川, 中国
}

\begin{abstract}
摘 要 教育转化问题学生, 是教师工作的一项重要任务。教育者要力争最好, 不断更好; 融会贯通, 左右逢源; 做好本职工作, 清正廉洁。面对问题学生, 教育者先要倾听, 要善于察言观色, 主动承担责任, 再用关爱、循循善诱、开导的以理服人唤起他的进取 心、自信心使之改正缺点, 然后引导并激励他积极向上、遵章守纪、尊师重教, 才能使之成为品学兼优的学生。和学生谈心要尽量选 一个适宜谈心的地点, 不遗留、不上交矛盾, 指出光明的前途, 要随机应变。
\end{abstract}

关键词＼cjkstart问题学生、思想政治教育、案例、基础、原则。

作为教育工作者, 难免不遇到一些出现了问题的学生。 教育转化问题学生, 是教师工作的一项重要任务。教育只 有用关爱、循循善诱、开导的以理服人唤起他的进取心、 自信心使之改正缺点, 然后引导并激励他积极向上、遵章 守纪、尊师重教, 才能使之成为品学兼优的学生。问题学 生是指那些与同年龄段学生相比, 由于受到社会、家庭、学 校等方面的不良影响及自身的存在的需要改进的因素, 从 而导致在心理、认识、思想、行为、学习等方面偏离常规, 需要别人帮助才能解决问题的学生。首先表现在思想品德 方面, 主要表现在学习、心理、行为方面。由于他自己发 展需要及发展潜能没有得到应有的实现, 不能或基本不能 完成教育和学习任务的学生。这样的学生往往表现为思想 品德不高, 学习成绩差, 经常违反学生日常行为规范, 有 违法乱纪行为, 等等。而其中偏激, 失去理智, 不服管教, 甚至威胁教师的学生是问题学生的典型情况, 正在滑向违
法犯罪的边缘。不过, 只要他还没有付诸行动, 就还没有 犯罪, 而这时候只要措施得当, 极易使他悬崖勒马, 迷途 知返, 成功避免一场重特大事故的发生。

面对已经失去理智的学生, 我们应该怎么办呢? 这里, 先讲一个笔者曾经亲身经历的一件事情, 也就是一次成功 而真实的实践。然后在这基础上总结出经验教训, 并上升 为理论, 以指导实践。有案例才有真实性、吸引力和说服 力, 因为事实胜于雄辩。

\section{1. 对问题学生的成功教育案例}

2008年6月21日下午, 从中国南方某校F1系办公室一一 该系操场处的校门之间大概有 $4 、 5$ 百米的距离之间的路段, 人物就是笔者和该校 F 1 系某班的 $1 \mathrm{jg}$ 同学。

事情经过, 就是笔者所教的那门课程考试完后, 笔者 正在 $F 1$ 系办公室清理试卷袋, 就听人说有学生威胁监考 $\mathrm{sh}$ 
老师 “让你一辈子后悔!” 紧接着, 该班的科代表、学习委 员和那个威胁老师的学生 $1 \mathrm{jg}$ 就来到了 F1系办公室。他们问 候笔者以后, 副班长和学习委员就主动给笔者清理试卷袋。 笔者就听旁边的Y老师说 “为什么要作弊嘛? 不是开卷考试 吗? 专业课都没有这么上心! 还威胁监考 sh老师 “我要让 你后悔……' ! ’ 老师话还没有说完, $1 \mathrm{jg}$ 嘴里就吹里咕噜 的, 不知道他在说什么, 因为他的情绪已经失控, 太激动 了。1jg性子本来就比较急躁, 在当时那种情况下, 再激动 起来, 说的话就更难让人听得懂了。笔者立刻就适时介入, 对他说道: “态度要端正哈!” 他马上就不再说话、静静地 站在那里, 停止了无畏的争辩。他没想到笔者会这样说, 对他可能有点突如其来。等笔者收拾完考卷走的时候, $1 \mathrm{jg}$ 就如梦初醒般地追出来抢过笔者手中那重重的密封好的考 卷, 坚决要送笔者, 还说有话要给笔者说! 盛情难却, 不 得不让他给笔者提考卷。

在路上，师生一路说着，笔者只能简单地询问一下. 不知不觉就来到了 F1系操场边的校门处。Ljg 说要把笔者 送到家里面, 好今后到乐山的时候来看笔者。笔者不同意 他送到家里面, 因为怕他出意外, 尤其考虑到他还没有吃 晚饭。笔者想, 不能再让他送了。正好, 校门那里有一张 椅子。 $1 \mathrm{jg}$ 就要笔者坐, 但是笔者无论如何又要让他坐。争 执不下, 笔者就说 “必须你坐! 因为你比我小, 年龄小的 应该要受到照顾”。还是门卫送了一张椅子来, 让师生二人 面对空旷而令人心旷神怡的操场坐下了, 从而才使让坐的 争执结束了。

笔者对 Ljg 说 “你有什么委屈, 就告诉我”! 虽然他 由于还比较激动, 仍然说得不清不楚, 还说要找院长、书 记, 但是笔者终于还是抓住了他叙述中的存在问题的主要 部分: 就是在考试笔者所教那门学科的时候, 他向前面的 同学借书, 监考 $\mathrm{sh}$ 老师就马上收了他的卷子。在此种情况 下, 他就威胁监考 sh 老师 “我要让你后悔一辈子!” 鉴于 此, 笔者对他说道: “虽然是开卷考试, 但是同学之间不能 随便借东西, 只能自己查资料, 翻书。实在要借东西, 就 必须先举手, 征得老师同意才行!” 说到这里, Ljg低下了 头, 开始知道自己错了。趁热打铁, 笔者又说: “你出差错, 我也有责任, 就是我认为你们是大学生了, 而且是比较好 的班级, 就忽略了讲开卷考试的注意事项。” 笔者这样主动 承担责任, $\mathrm{Ljg}$ 不仅没有怪罪笔者的意思, 反而眼眭里滚动 着晶莹而感激的泪花。笔者继续说: “我一直认为你是最尊 敬老师的学生之一, 因为你经常从底楼给我提那装满讲义 的重重的包包到7楼。你还曾经给我说 “从我这里学到了许 多东西, 喜欢听我讲课”。笔者继续说道: “监考老师没 有什么错, 错的首先是我, 然后才是你。再说, 你可能把
问题看得太严重了, 即使这一次没有及格, 还可以补考, 不会影响毕业”。

如果笔者不是这样说, 而是直端端地, 简单粗暴地说 “开卷考试也有纪律, 这是连小学生都知道的道理, 就你 不知道!”那肯定会引起 Ljg 的反感, 思想政治教育的目 的就没有达到, 可能会出现一些意想不到的景况发生。

笔者还郑重其事地告诉他, 要做好最终还是不及格而 补考和接受学校处分的准备。Ljg 就说准备给监考 sh老师 写信道歉, 以求得谅解!

这时候, Ljg还是坚持要把笔者送到家, 但是笔者说: “后门出去就是 $\mathrm{jj}$ 厂宿舍那黑咕隆咚的楼道。如果你送 我, 把我送到了家, 但等一会儿你回来要一个人走那你从 来没有走过的楼道, 我怎么放心? ” 这样说了, 他才同意 不再送笔者了。不过, 他要目送着笔者先离开。笔者就说: “年龄大的要照顾年龄小的, 你年龄小, 应该你先走! 来! 我看到你离开!” 终于, 他开始离开了, 但他的离开可是一 步一回头啊! 笔者的声音 “回去吃饭以后, 要记得给我打 电话报平安啊!”传过去在空旷的原野留下了久久的回音。 直到现在, Ljg 都还在工作之余, 还要从那遥远的much县 打电话问候笔者。

\section{2. 思想政治教育成功的基础}

笔者认为, 以上实践比较成功, 令人信服和满意。那 么, 能够成功的基础有哪些呢?

\section{1 力争最好, 不断更好}

教育工作者要一步一个脚印地做好自己教育教学工作 方面的每一件事, 要力争最好, 不断更好! 每一件事后, 每一节课都要回顾提高, 尤其要找出做得不够完美的地方, 以求达到天衣无缝, 完美无缺的最高、最好、最理想的境 界! 这样, 毫不松解地长期坚持, 并且做好坚持一辈子的 准备, 就必将能够进入一个令人满意的境界和程度! 坚持 数年, 必有好处; 坚持一辈子, 就更有好处! 才能达到左 右逢源, 随机应变的境界, 才能得到学生的崇敬。

\section{2 融会贯通, 左右逢源}

要学习各种先进的教育教学理论和管理经验, 要兼收 并蓄, 创新提高, 尤其要融会贯通。现在, 知识更新的周 期越来越短, 知识量越来越大, 这被人们称为知识爆炸、 信息爆炸的年代。知识更新的周期越来越短, 就需要经常 学习, 不断提高自己的职业素质, 以获取最新的理论、信 息的熏陶和支持。知识量越来越大, 就需要讲究学习的方 法, 既要沉得下去悉心钻研, 又要能够跳得出来浏览式的 泛读。为什么又要创新呢? 因为只有创新, 才能不断完善, 
不断提高, 不断前进! 还因为别人的成功经验毕竟是特定 环境下的产物, 而要用来指导自己, 还需要创新, 加工制 作, 才能成为自己的东西, 从而得心应手地指导自己的教 育教学工作！创新首先就要融会贯通。融会贯通所学、所 见、所闻、所历、所思、所创、所有等, 才能左右逢源, 随机应变, 临场发挥。不融会贯通, 就是读死书。

\section{3 做好本职工作, 清正廉洁}

作为教师, 要备好课, 讲好课, 力争得到大多数学生 的佩服、信任和喜欢。这样, 学生能从内心深处喜欢你, 接近你, 尊敬你。遇到什么问题, 你就是批评他几句, 他 也会乐意地接受, 不会产生怨恨, 也不容易产生逆反心理。 在2007学年度下期末, Ljg 所在班级举行座谈会的时候, 面对许多同学和老师, 他对笔者说: 非常喜欢听笔者讲课, 学到了许多做人的道理, 十分感谢! 实习以后的 2008 年 7 月6日 Ljg 同学在QQ上问候笔者 “你过的还好不啊老师？” 在QQ上, 他还对笔者说 “学生真的很想你啊”、“老师! 真 的很感谢你这年的关心哈? /”、“老师! 你的关心你的教导 学生不回忘记你的”、“我要走了, , , 祝你天天开心, , 身 体健康老师” 真是多乘的孩子, 多好的学生啊! 当时, 笔 者都感动得热泪盈眶, 有点控制不住自己了!

虽然得到了大多数学生的佩服、信任和喜欢, 作为人 类灵魂工程师的教师来讲, 也还是要小心谨慎、精益求精、 坚持原则、公平正义、两袖清风、清正廉洁。2008年6月份, Ljg 同学所在班有同学公开说, 要去实习, 和笔者要分别了, 打算今后来看笔者, 还说要来给笔者祝贺生日! 笔者当即 就说: “我最大的希望就是: 你们找到理想的工作, 并且把 工作干好! 这才是对我最大的祝贺。不用来看我, 更用不 着来给我祝贺生日!” 不管是学生出于真心, 还是想试探, 作为人类灵魂工程师的教师都应该旗帜鲜明地表明自己的 态度予以抵制, 以保证人民教师在学生心目中的完美形象, 从而赢得学生真正地拥戴, 也才能坐得端, 行得正。

\section{3. 指导实践成功所用的理论和原则}

以上实践比较成功, 令人信服和满意。那么, 笔者又 采用了哪些方法和原则, 做了些什么呢?

\section{1 尊重学生, 付出师爱}

每一个人都需要得到尊重, 学生更应该得到尊重。这 样, 学生才能认同接纳教育者, 才能建立一座师生心灵相 通的爱心桥梁。有了这座桥梁, 学生才会没有保留地把自 己的内心和盘托出; 教师才能分析, 寻找对策, 实施有效 的思想政治教育。没有这座桥梁, 学生不愿意讲, 教师就 无从了解情况, 难以实施有效的教育。思想政治教育既需
要技巧, 更需要充满了人情味的师生心灵交融。心理学家 认为 “爱是教育好学生的前提”。对于 L jg 这样特殊的易 于冲动的后进生笔者放下架子亲近他, 敞开心扉, 以关爱 之心来拨动他的心灵之弦。“动之以情, 晓之于理”, 促使 他自觉认识并改正错误。

一条永恒的、铁的红线就是尊重学生, 不伤学生的自 尊心。教师不能居高临下, 以长者自居, 而要和学生平等 相处, 甚至教师可以做出自己年龄大, 就该处处让着点的 高姿态。这会更加赢得学生的崇敬, 真是退后一步自然宽。 对学生, 要多用商量、劝告、疏导的口吻, 一定要做到以 心换心, 促膝谈心。尤其是在学生已经失去理智, 又自以 为是的情况下, 更是如此。要让学生尽量把话说完, 而且 教师要仔细倾听, 以扑捉自己说话, 实施思想政治教育的 切入点!

\section{2 要倾听, 要善于察言观色}

当时, 笔者正在清理考卷, 猛然听到 $1 \mathrm{jg}$ 在顶嘴, 并且 由于情绪激动, 说得前言不搭后语。笔者再仔细一瞧, 他 脸红脖子粗。很明显, 他已经失去理智, 就是认为自己没 有错, 好像受了天大的委屈一样。笔者想, 那么乘的学生, 怎么会这样, 许多念头和方案在笔者的脑海里一闪而过, 终于笔者脱口而出 “态度要端正哈!”从而有效地结束了 $1 \mathrm{jg}$ 那不理智的绞辩, 使他安静下来, 从冲动失控的悬崖边勒 住了缰绳。“态度要端正哈!”不是强迫式的命令、呵斥和 指责, 而是有一种商量、劝告、希望和安抚的口吻。如果 把 “态度要端正哈!”换成 “你给我老实点!”、“把嘴巴闭 到!” 等命令式的口吻, 容易使学生产生逆反心理, 其效果 肯定就不会好。

\section{3 要选一个适宜谈心的地点}

这个谈心地点最好是一个开阔、幽静、绿树成阴的地 方。这会给学生一种心旷神怡, 能够使他不愉快心情在这 样的美景中已经消失大半的感觉。开阔、幽静的环境会使 学生觉得保险, 不会被人偷听, 不会丢面子! 而我和 $1 \mathrm{jg}$ 促膝谈心的主要地点—-F1系校门内操场, 就是一个幽静 而开阔的地方, 是一边走一边寻找的结果。

\section{4 教师自己要主动承担责任}

教师不能认为在学生面前承认了自己的不足, 就是丢 面子。教师要诚恳地把自己做得不够的地方告诉学生。笔 者当时说 “如果我考前在你们班讲了开卷考试的注意事项, 那就不会出现今天的意外”。 Ljg 看笔者主动承担责任, 脸上的愁容就消去了不少。 


\section{5 尽量不遗留, 不上交矛盾}

虽然笔者不在事发现场, 就不能认为事不关己, 高高 挂起。不能认为: 在我面前是好学生, 怎么到了你那里就 是坏学生? 更不能幸灾乐祸, 隔岸观火。而是要积极主动 地参与解决, 把问题和矛盾尽量解决在自己那里, 不遗留, 不上交。当 $1 \mathrm{jg}$ 说要找院长、书记的时候, 笔者就告诉他, 全院近万学生, 如果每一个人都去找, 就难以应付。再说, 我们学院有严密的组织管理机构, 我们的老师就是受党和 人民的委托, 代表院长、书记来教育、培养学生的。不到 万不得已, 不要动不动就去找院长、书记。同时, 要注意 维护学校、领导和相关教师的权益和安全。

\section{6 指明前途是光明的}

笔者告诉 $1 \mathrm{jg}$ “就是不及格, 还可以补考。即使因为 这件事受到了学校处分, 也可以痛改前非, 不会影响你顺 利毕业!”接着, 当笔者告诉 $1 \mathrm{jg}$ 要做好最终还是不及格 补考和接受学校处分的准备的时候, 他就没有因为绝望而 失去理智。

\section{7 随机应变}

在教育教学方面要做到随机应变、举一反三和创新。 这就需要注意力经常高度集中, 对学生、对课堂、对教育 教学的规律、环节、内容和要求熟能生巧、融会贯通, 也 才能左右逢源、得心应手。

\section{8 因材施教，循循善诱}

Ljg的情况比较特殊, 主要是组织纪律性不强, 对自己
的缺点、错误认识不足, 对老师的严格要求产生厌恶、抵 触、憎恨心理, 甚至发展为威胁。故此, 笔者就以爱心为 中介, 搭建师生心灵相通之桥。与他交朋友, 谈心, 主动 承担责任, 这叫以退为进; 再使其认识错误, 树立成功成 才的信心; 充分挖掘 Ljg 的优点, 尤其多说他与笔者在平 时的深情厚谊, 使他打消对教育者的防范、隔阂心理, 让 他感到老师的关心、重视……用关爱唤起他的自信心、进 取心, 使之改正缺点, 然后引导并激励他积极向上, 争取 成为品学兼优的学生。

另外, 不能有侥幸心理, 不能因为是好班, 就省去教 育教学的环节和内容, 不能掉以轻心; 在融洽、友好、和 谐的师生关系中, 再指出学生错误的性质、根源和解决的 措施; 多回顾学生过去的优点, 多提及学生过去尊师重教 的点点滴滴, 以表明老师对他没有成见, 对他是喜欢的。

\section{参考文献(References)}

[1] Guojie Luo, Weidong Xia, Kailin Tang, Binggong Chen and Qiantao Chen: "Ideology and moral cultivation and law foundation", Higher Education Press, 2013 revision.

[2] Shuqing Wu, Zhanan Chen, Keqin Tian, Guiqing Xiao and Xuan Qin: "Introduction of Mao ze-dong thought and theoretical system of socialism with Chinese characteristics", Higher Education Press, 2013 revision.

[3] Kailin Tang and Naiping Jiang: "Occupation moral and occupation guidance”, Higher Education 2013.

[4] Liyu Zhu and Wei Zhang: "Occupation morals and law", Higher Education 2009 